\title{
Managing the Selenium Content in Soils in Semiarid Environments through the Recycling of Organic Matter
}

\author{
R. Garcia Moreno, ${ }^{1}$ R. Burdock, ${ }^{2}$ María Cruz Díaz Álvarez, ${ }^{3}$ and J. W. Crawford ${ }^{2}$ \\ ${ }^{1}$ Faculty of Sciences, University of La Coruña, Zapateira, 15001 A Coruña, Spain \\ ${ }^{2}$ Judith and David Coffey Chair, Faculty of Agriculture, Food and Natural Resources, University of Sydney, \\ Suite 411 Biomedical Building, 1 Central Avenue, Australian Technology Park, Eveleigh, Sydney, NSW 2015, Australia \\ ${ }^{3}$ CEIGRAM (Centre for Studies and Research on Agricultural and Environmental Risk Management), \\ School of Agricultural Engineering, Polytechnic University of Madrid, Ciudad Universitaria S/N, 28040 Madrid, Spain \\ Correspondence should be addressed to R. Garcia Moreno; rosario.garcia@upm.es
}

Received 29 June 2013; Revised 2 September 2013; Accepted 14 October 2013

Academic Editor: Philip J. White

Copyright ( 2013 R. Garcia Moreno et al. This is an open access article distributed under the Creative Commons Attribution License, which permits unrestricted use, distribution, and reproduction in any medium, provided the original work is properly cited.

\begin{abstract}
Around $30 \%$ of the world's population suffers from either a lack of one or more essential micronutrients, or the overconsumption of these minerals, which causes toxicity. Selenium (Se) is a particularly important micronutrient component of the diet with a well-documented and wide-ranging role in maintaining health. However, this important micronutrient can be lacking because soil and crop management are focused on high yields to the detriment of the quality of crops required to ensure a healthy human diet. Currently around $15 \%$ of the global population has selenium deficiency. This paper focuses on Se availability in semiarid soils and how micronutrients can be effectively managed through the recycling of organic matter. Because many mineral reserves are being exploited unsustainably, we review the advantages of using organic by-products for the management of the biofortification of Se in crops. This type of practice is particularly useful in arid and semiarid environments because organic matter acts as a reservoir for Se, preventing bioaccumulation and leaching. There are also potential local economic benefits from using organic by-products, such as manures and sewage sludge.
\end{abstract}

\section{Introduction}

At least $60 \%$ of the world's population either lacks one or more essential mineral elements or consumes food containing high amounts of toxic mineral elements [1]. Mineral malnutrition is a widespread problem in both developing and developed countries. This situation is particularly serious for some micronutrients, such as $\mathrm{Fe}, \mathrm{Zn}, \mathrm{I}, \mathrm{Se}, \mathrm{Ca}, \mathrm{Mg}$, and $\mathrm{Cu}$ $[2,3]$. In the specific case of Se, $15 \%$ of the world's population is already Se deficient [2].

Gupta et al. [4] stated that, in addition to the lack of studies on the ability of plants to uptake minerals, there are insufficient analyses of soil that determine the total nutrient contents. Similarly, there are no studies of the impact of different soil management practices on the concentration and distribution of micronutrient concentrations in the different edible parts of crop plants.
The micronutrient status of a plant can be measured from the leaves because leaves contain the highest amounts of micronutrients. Micronutrient deficiency is easily detected in younger leaves, whereas toxicity can be detected in later stages of development in older leaves [5]. Several factors control the lack of Se content in plants including the genetic variety, soil management, soil type, and climate. The lack of micronutrient content in plants is common in humid temperate and tropical regions due to intense soil leaching caused by the high number of rain events.

Ekholm et al. [6] studied the trends in the mineral and trace element contents in fruits, vegetables, and cereals in Finland over the last 30 years. They found that the content of most minerals has decreased in all crops. Interestingly, the only exception is Se, the content of which has increased as a result of the use of selenium-supplemented inorganic fertilisers over the last 20 years. Tennant et al. [3] found 
the same pattern of decline in UK crops and noted that analogous trends have occurred in different countries that share very similar historical farming management strategies, based mainly on the adoption of modern genetic varieties of crops and agronomic practices related to the acceleration of the growth rates of plants. These practices include growth in higher temperatures, increased light intensity, increased $\mathrm{CO}_{2}$ concentrations, and higher irrigation rates.

Micronutrient cycling in soils is closely related to the organic matter content and crop residue management [7]. Therefore, soil and crop mismanagement that leads to the loss of organic matter leads to a reduction in the mineral content of soils and consequently the mineral content of plants. Biofortification can be achieved either through the use of genetically improved crops for mineral uptake into the edible parts of the plant or through the use of specific fertilisers that increase the phytoavailability of some minerals to specific crops [2]. However, inorganic fertilisers are increasingly expensive to manufacture, distribute, and apply. These fertilizers also have environmental impacts, including an increase in greenhouse gas emission, the unsustainable exploitation of mineral resources, and the mineral enrichment of the environment leading to soil contamination. Biofortification is mainly dependent on the specific chemical forms of micronutrients in soils and the subsequent uptake by plants [8]. To reinforce this strategy, it is necessary to know the forms of the mineral elements that are available to plants, as well as the limitations and the phytoavailability of these elements in the rhizospheres [9]. In the specific case of selenium, the plant roots will obtain this element through the uptake of selenate, selenite, or organoselenium compounds by the plant roots [3]. Agronomic biofortification strategies to increase the mineral concentrations in the edible parts of plants generally rely on the application of mineral fertilisers and the improvement of the solubilisation and mobilisation of soil micronutrients. In the case of selenium, the application of soil and foliar Se fertilisers has been shown to have beneficial effects on animal health and human nutrition. Soil applications are suggested for cropping under late-season moisture and heat stress $[3,5,6]$.

The consumption of many key minerals is unsustainable according to Hueso et al. [10], with current rates of consumption leading to the depletion of global mineral reserves in the next 50 years. According to the US Geological Survey [10], almost all of the selenium produced worldwide is currently recovered from anode slimes during $\mathrm{Cu}$ electrolysis and to a lesser extent during $\mathrm{Ni}$ and $\mathrm{Zn}$ electrolysis. According to this same source, the global Se reserves are $172,000 \mathrm{tSe}$, which is based on $\mathrm{Cu}$ deposits. Thus, if one-third of the world's arable land (500 Mha) is fertilised with $10 \mathrm{~g} \mathrm{Se} / \mathrm{ha}$, $5000 \mathrm{tSe} / \mathrm{yr}$ will be consumed, and the global Se reserve would be depleted in less than 40 years. Thus, the use of minerals as fertilisers has to be prioritised to ensure that the nutritional demands are achieved or other strategies must be implemented to avoid the exhaustion of mineral reserves. To these ends it is also important to obtain more information on the geographical distribution of micronutrients in relation to nutrient sampling in crops and the relationship with epidemiological studies to evaluate the relationship between animal

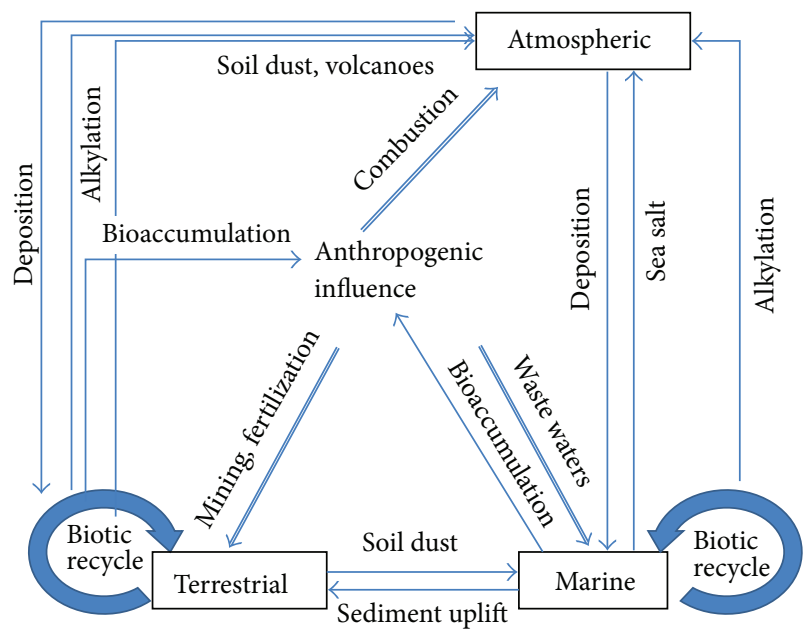

FIGURE 1: Global Se cycle considering the anthropogenic influence (extracted from [11]).

and human diseases and the geochemical environment and soil and plant management related to nutrition crops [5].

\section{Importance of Selenium in the Human Diet}

Se was discovered in 1817 by Berzelius; however, it was not until 140 years later that its nutritional requirement was determined [12]. The Se cycle is represented in Figure 1. Although Se is not essential for plant growth, this element has beneficial effects that promote the growth of plants and it is essential in a healthy diet for humans and other mammals [11]. In general, micronutrients, such as Se, are required as cofactors for enzymes or as part of the protein structure involved in DNA synthesis and repair, the prevention of oxidative damage to DNA, and the maintenance of the methylation of DNA [13]. Because of these functional roles, Se deficiency in mammals can result in several physiological disorders, such as cardiomyopathy (Keshan) and osteoarthritis diseases (Kashin-Beck), pancreatitis, asthma, inflammatory response syndrome, malfunctioning of immune system, decreased response to viral infections, and decreased fertility and thyroid functioning [13].

The individual human Se intake ranges from 3 to $7000 \mu \mathrm{g} \mathrm{Se} /$ day worldwide, with most cases at the lower end of the range [14]. For beneficial effects, the US Government recently recommended dietary Se allowances of 55 and $70 \mu \mathrm{g} /$ day for women and men, respectively [12] and the current standards designated by the Department of Health (1991) in the UK set the upper safe limit to $400 \mu \mathrm{g} \mathrm{Se} /$ day/person. Broadley et al. [15] noted that the Se intake in the UK has declined from $60 \mu \mathrm{g} \mathrm{Se} / \mathrm{d}$ to $29-39 \mu \mathrm{g} \mathrm{Se} / \mathrm{d}$ by the end of the 90 s, and in other EU countries, the intakes are even lower at 30 and $38 \mu \mathrm{g} \mathrm{Se} / \mathrm{d}$ for females and males, respectively, based on the results of blood and serum testing.

Most of the researches conducted on Se and human health report a beneficial effect of this element in the prevention of cancer and cardiovascular disease [15-22]. Against this, Wu et al. [23] did not find any beneficial effects in human 
Australian males who consumed a supplementary Se diet with biofortified wheat $(193 \mu \mathrm{m} / \mathrm{L})$. In these individuals, the beneficial effects were tested through biomarkers of cancer and cardiovascular diseases. However, as the authors noted, any beneficial effects may have been related to specific genotypes, and further studies are needed to confirm the conclusions. Se deficiency has been associated with liver, muscle, and heart disease in animals [24]. As mentioned, Se has one of the narrowest ranges in humans between dietary deficiency and toxic levels: less than $40 \mu \mathrm{g} \mathrm{day}^{-1}$ to more than $400 \mu \mathrm{g} \mathrm{day}^{-1}$ [25]. Thus, although global Se toxicity in humans is far less widespread than Se deficiency [26], it is still important to understand the biophysicochemical processes that regulate its bioavailability in nutrition [27]. Furthermore, Se is chemically similar to sulphur in plants and it is therefore metabolised through many of the same pathways, with many plants preferentially uptaking Se over S. Above a critical leaf dry matter concentration in the range of 10 to $100 \times$ $10^{-3} \mathrm{mg} \mathrm{Se} / \mathrm{kg}$ plant dry weight, selenium toxicity begins to limit growth in most plants. Se toxicity in crops occurs mainly on seleniferous soils, and only plants that exhibit genetic tolerance to this type of soil can be successfully grown $[2,7]$.

The selenium level in most soils is generally less than $1 \mathrm{mg} \mathrm{Se} / \mathrm{kg}$ soil; however, the selenium content in seleniferous soils can be as high as 4 to $100 \mathrm{mg} \mathrm{Se} / \mathrm{kg}$ soil. The selenium content of plants in most soils is less than $1 \mathrm{mg} / \mathrm{kg}$ plant dry weight, whereas most plants grown in seleniferous soils show selenium levels in the range of 1 to $10 \mathrm{mg} / \mathrm{kg}$ plant dry weight. In the case of Se-hyperaccumulator plants, this can increase to between 1000 to $15,000 \mathrm{mg} / \mathrm{kg}$ [7]. These differences in concentration can be visualized in Figure 2, which shows potential areas where livestock may be at risk for selenium deficiency or toxicity in Australia. The major species of Se in plants include selenate, which is translocated directly from the soil and is less readily bound to soil components than selenite, and selenomethionine (SeMet) and selenocysteine (SelCys), both of which are biosynthesised by plants $[15,28]$. The Se content in wheat and other cereals is in the form of SeMet with lower amounts of SelCys and selenate. Se-enriched crops exhibit a higher Se content than the corresponding natural plants; nevertheless, the treatment of crops must be performed with caution to reduce the risk of toxicity [29].

The absorption of Se in humans is not affected by the nutritional human status and approximately $80 \%$ of the absorbed selenium originates from food. The studies that have compared the bioavailability of different forms of Se in humans concluded that organic forms are more bioavailable than selenate and selenite $[24,30]$. In fact Se-methylselenocysteine and its $\gamma$-glutamyl-derivative, which are found in a number of edible plants of the Allium and Brassica families, have been studied for their potent anticancer effects. These selenoproteins have very high antioxidant properties and are highly beneficial in counteracting diseases related to oxidative stress. As well as the benefits from selenoproteins, the Se obtained in the diet can be metabolised to smallmolecular-weight species that are believed to exhibit antitumour effects [30].

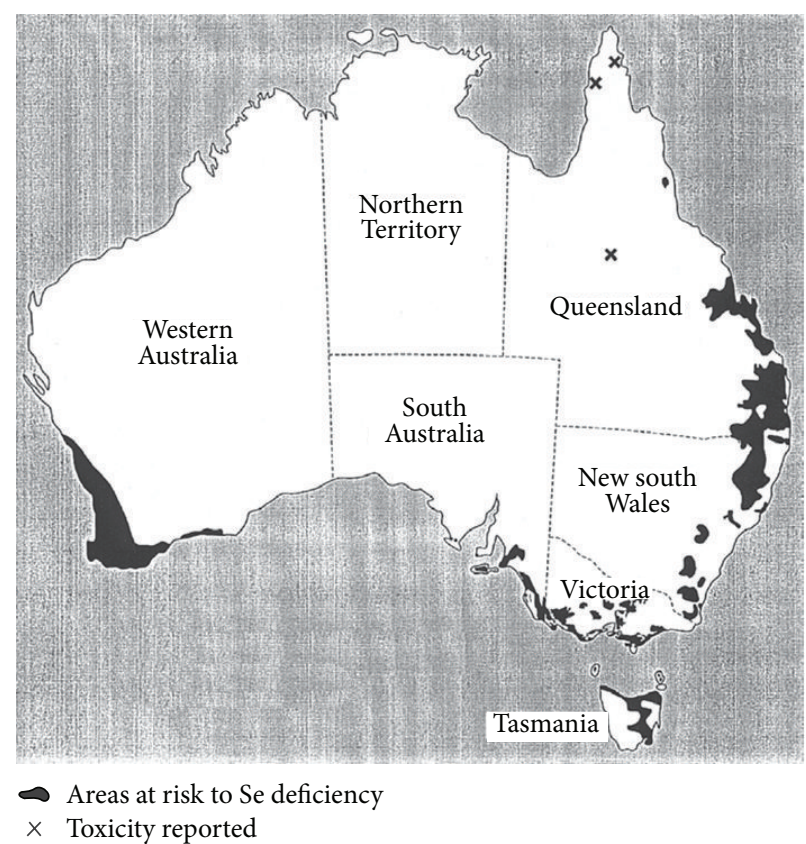

Figure 2: Map of Australia showing potential areas where livestock may be at risk for selenium deficiency or toxicity (extracted from [34]).

At sufficiently high doses, the Se metabolites can also induce toxicity in animals and humans. The effects of the Se toxicity are highly dependent on the form of Se. Se compounds can easily form an anion that generates superoxide in the presence of thiols, such as glutathione, which results in redox cycling. Studies have shown that the toxic effects of Se are due to this oxidative-stress mechanism [31, 32]. In fact, superoxide has been shown to be generated from selenite and diselenides, such as selenocysteine, but not from selenite, in the presence of reduced glutathione [31, 32]. As a result of their inability to generate superoxide, SeMet nor Se-methyl-selenocysteine has a relatively low toxicity to cells in culture or to animals or humans. Nakamuro et al. [33] found that selenodiglutathione, which is an intermediate chemical species in the formation of superoxide from selenite and glutathione, is more toxic than selenite itself. Hasegawa et al. [34] found that another mechanism of Se toxicity includes the inhibition of Se methylation, which represents the major detoxification pathway for Se; the inhibition of this pathway results in the accumulation of selenide hepatotoxic compounds. Although studies on Se toxicity suggest that the organic forms may be more toxic than the inorganic forms after long-term consumption because the organic forms are more easily incorporated into tissues, there is no conclusive evidence that proves this hypothesis [34].

Finally, as noted by Rayman [29], it is difficult to define the optimal intake of Se at the individual level because its concentration in the body is dependent on a large number of factors, such as which functions of Se are most relevant for a certain stage of a disease, which species of Se is predominant in the Se source, the health conditions in the receptor, the adequacy of intake of other nutrients and their interferences, 


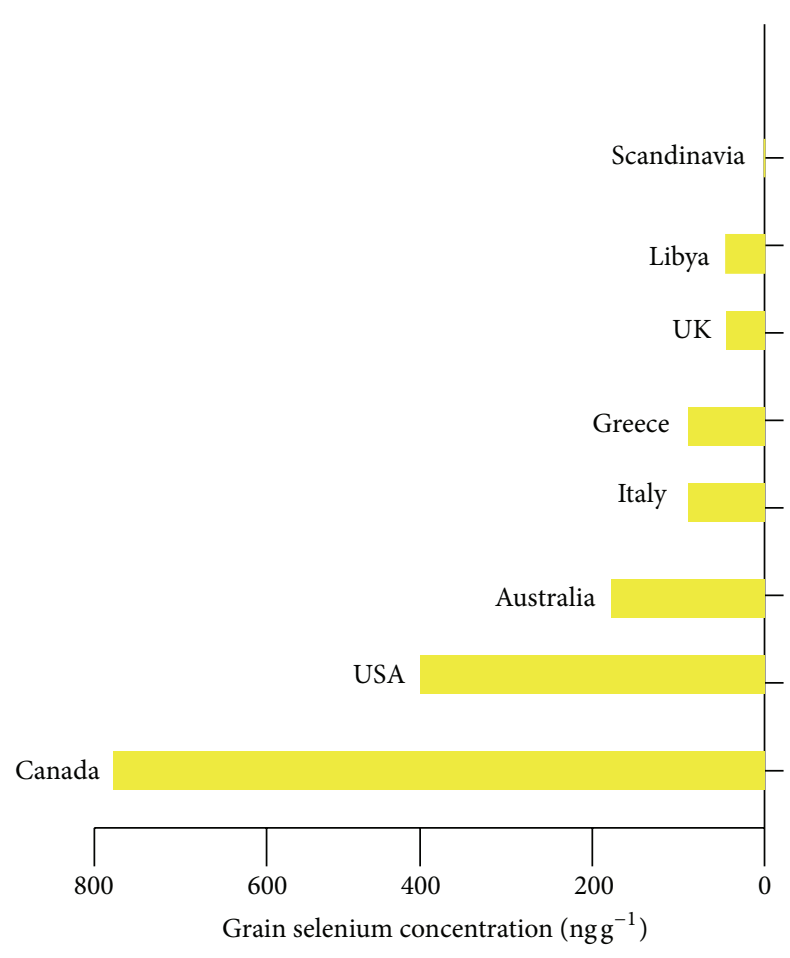

(a)

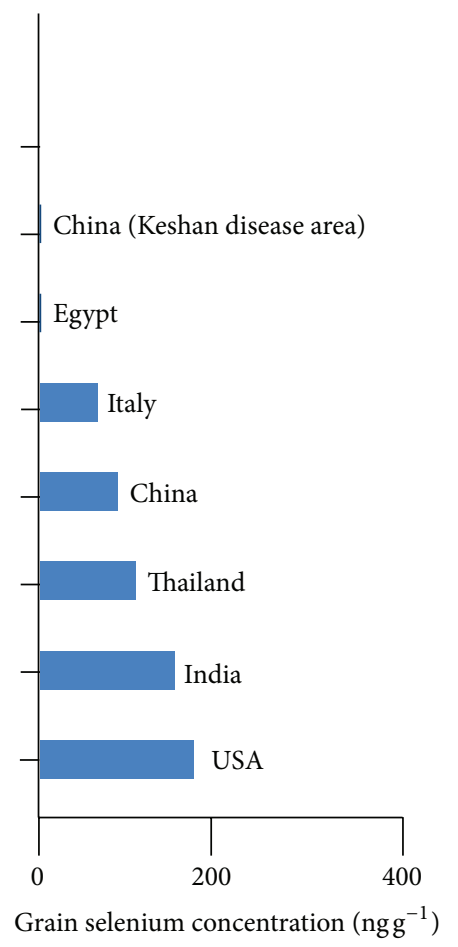

(b)

Figure 3: Comparison of Se levels in wheat (a) and rice grains (b) in different countries over the last 40 years (extracted from Zhu et al. [35]).

the presence of additional stressors, and the ability to produce selenoproteins.

\section{The Role of Soil Fortification}

According to Levander and Burk [21], wheat (Triticum aestivum L.) represents the major dietary source of Se worldwide and therefore the decrease in Se intake has been related to changes in the Se content of cereal grains and to the decrease of Se in soils. This hypothesis is supported by decreases in intake and the trend over time in the UK to consume a larger proportion of grain grown in the UK that has a lower Se content compared with imported grain grown in North America, where the soils contain higher amounts of Se [15]. Zhu et al. [35] made a comparison of the Se content in rice and wheat between different countries and crops over the last 40 years, as shown in Figure 3.

Lyons et al. [31] proved that the fertilisation of wheat crops in Australia with Se fertilisers is a cost-effective method for the improvement of the concentration of organic Se in grain, which results in an incremental uptake of Se in animal and human diets. As mentioned above, the important issue associated with the management of Se fertilisation is the control of the amount of Se added to avoid toxicity. The authors added $\mathrm{Se}$ in the form of selenate at fertilising rates of up to $120 \mathrm{~g} / \mathrm{ha}$ in field trials and $500 \mathrm{~g} / \mathrm{ha}$ in pilot trials in soil and added $330 \mathrm{~g} / \mathrm{ha}$ of foliar Se applied with low $\mathrm{S}$ concentrations $(2-5 \mathrm{mg} \mathrm{S} / \mathrm{kg}$ soil). These researchers did not observe any symptoms of toxicity in the crop even if the application is 20 times higher that safest applications. A soil application of $10 \mathrm{~g} \mathrm{Se} / \mathrm{ha}$ is found to be safe for raising Se content of crops in Finland.

In the case of Se applied as selenite, they observed a critical amount of $70 \mathrm{mg} / \mathrm{L}$ required to cause growth inhibition, whereas selenate did not affect the crops in a solution concentration of $150 \mathrm{mg} / \mathrm{L}$. They recommended using application rates of $200 \mathrm{~g}$ selenate/ha to avoid toxicity in wheat and to obtain tissue levels of Se below any toxic concentration. In later studies, Lyons et al. [36] found that the concentrations of Se in diverse germplasms did not vary in different cultivars and was in the range of 5 to $720 \mu \mathrm{g} / \mathrm{kg}$, regardless of the genotypic variation.

Finland has conducted fortification of crops since 1981 and has obtained excellent results: only the Se content exhibited an increasing trend in different crops compared to the decreasing trend in the concentrations of other micronutrients of up to 10-fold in most crops [6]. Eurola et al. [37] measured the Se content in 125 food items before and after fortification in Finland and found that the Se content had increased in all cases. The total intake was distributed across cereals (26\%), meat (29\%), dairy products (20\%), eggs (10\%), and fish (9\%). In addition, only those diets with a very exceptional composition provide less than $0.05 \mathrm{mg}$ or more that $0.2 \mathrm{mg}$ of Se per $10 \mathrm{MJ}$ (Mega Joules). In the case of cereals, of which wheat is the most important, their contribution to the total intake of Se almost tripled from 1971 to 1991. The biofortification of pastures and forages has been shown to increase the Se content in the diet by increasing the Se content 
in livestock $[4,5]$. The last authors demonstrated that Se content in pastures and forages prevents disorders amongst grazing livestock, such as muscular dystrophy disorders.

Broadley et al. [38] used selenate fertiliser in wheat crops and found that the crop total recovery, including grain and straw, ranged from $20 \%$ to $35 \%$. These researchers added up to $10 \mathrm{~g} \mathrm{Se} / \mathrm{ha}$ to the crop, and, if the straw is removed, approximately $6.5-8 \mathrm{~g} \mathrm{Se} / \mathrm{ha}$ is not recovered. For this reason, to ensure the long-term sustainability, the fate of Se in soils and in the food chain must be known before any biofortification strategy is widely implemented. The residual Se may be leached, volatilised, retained in the soil, strongly absorbed by iron or aluminium oxides, or retained in the soil in nonsoluble elemental forms.

Eurola et al. [37, 39] concluded that Se fertilisation significantly affects the Se content of cereals and other crops. However, the same authors also noted that the Se content varies considerably on an annual basis and between different locations mainly due to the specificity of the fertilising rates and the different soil and climatic conditions.

It is clear that there are individuals and populations that would benefit from a higher Se intake level. However, it is important to be aware of the specific geochemical environment and the baseline intake in any specific country or region because necessary additional intake in one region or country might be excessive in another [18]. Beside these health-related considerations, other elements that should be considered are the cost-effectiveness of adding Se to food sources, such as through biofortification or the recycling of organic by-products, and the environmental effects of the fertiliser and soil management strategies. For example, if the Se fertilisers are economically and environmentally expensive, other sources of recycling, as well as the management of different soils to conserve and retain the surplus of Se in soils to avoid their lost through leaching, evaporation, and absorption, must be considered.

\section{Se Management for Crop Fertilisation in Semiarid Environmental Conditions}

In the case of semiarid and arid environments, the lack of micronutrients and macronutrients in crops is mainly due to high crop yield, insufficient return of crop residues to soil, low organic matter, and immobilisation of most micronutrients in the soil [3]. This is the situation in most Australian soils used to produce cereals [14], especially those used to produce cereals in the southern regions, which are mainly alkaline and particularly calcareous or sodic. These conditions drive chemical constraints for agricultural production associated with the alkaline soil environment and the dry land climate, which include macronutrient and micronutrient deficiencies and some toxicity related to high sodicity and salinity. More generally, alkaline soils represent an important proportion of world soils that sustain crop production $[3,14,40]$. Most of these soil conditions have led to desertification in some parts due to an increase in the soil erosion and decreases in the soil fertility due to the depletion of nutrients related to the loss of organic matter and the biological diversification of soils [41]. Bowker et al. [41] noted that most of the problems related to desertification in arid and semiarid environments originate from anthropogenic disturbances that change the organic matter and biological properties of soil crusts. This is especially true for arid regions, where desertification is closely related to either a net loss in the soil fertility or a redistribution of the soil nutrients [42-44]. Bowker et al. [41] found that the micronutrient soil content is highly correlated to the biological activity and specifically to the presence of moss and lichen species in semiarid conditions. The distribution of these biological species is highly correlated to the moisture, organic matter content, and higher availability of micronutrients. The high degradation observed in arid lands can therefore be resolved by improving the biological diversity of soil through the management of the organic matter.

From this point of view, biological diversity and the management of the organic matter become important factors for the improvement of micronutrient availability in degraded lands. In most cases, the response of plant growth to the addition of macronutrients and micronutrients in semiarid and arid soils is highly positive [43]. In fact, the response to the addition of a heterogeneous nutrient supply must be optimised in each case by understanding the plant response and the bioavailability of each nutrient [43]. To monitor the addition of different concentrations of nutrients and their effect on plant growth, we need to understand how the nutrient concentrations in the plant respond to changes in nutrient supply. The effects of nutrients on plants can be easily determined by the ability of plants to translocate nutrients and to store pools in different parts of the plant. Thus, the ideal management of the micronutrients will require knowledge on how the different nutrients are specifically taken up by different plants and how the nutrients are stored and translocated inside the different plant parts, particularly the edible portions [27].

Another important issue associated with the availability of different nutrients in soil is the speciation, quantity, and distribution of the nutrient in different soils, as well as the effects of different chemical species on root growth and grain yield [27]. Modern agricultural techniques used to obtain higher yields worldwide are accelerating the depletion of nutrients and leading to an increase in the application of fertilisers to maintain production [45]. Li et al. [46] found that the micronutrient status in soils and crops is affected by fertilisations practices. Specific cases must be studied to determine how fertilisation practices can help improve the soil micronutrient and macronutrient states in order to manage the ideal rates of fertiliser application for in different crops. Research on cereal crops showed that it is possible to obtain higher yields with the application of organic fertilisers because these improve the soil organic matter and thus provide available micronutrients for crops. However, low yields of winter wheat were obtained when only the micronutrient contents were improved because these were highly concentrated in the plant tissues and grains [46]. Sustainable crop production needs to maintain the soil fertility on a long-term basis, and it is essential that the organic matter and nutrients removed during harvest 
are replenished through external application on a regular basis. Some authors recommend the maintenance of the soil organic matter at a threshold level, which will depend on the soil and climatic factors, to ensure the physical, chemical, and biological integrity of soil to achieve sustainable agricultural and environmental functions [47-51].

In semiarid and arid environments, some studies concluded that the presence of Se in plants has a protective effect that helps maintain the water status in plants exposed to drought [25]. In this case, selenium is hypothesised to participate in the regulation of the water status of plants and in maintaining the content of water in the tissues at a sufficiently high level [25]. The selenium-supplemented fertilisation of wheat crops in semiarid conditions is a costeffective method if inorganic fertilisers are used to ensure the ideal concentration of organic Se in grain as a result of dietary needs. Based on the research studies conducted on Se fertilisation as selenate (more mobile form of Se than selenite [52]) at different rates ( 4 to $200 \mathrm{~g} / \mathrm{ha}$ ), wheat does not express any phytotoxicity (critical tissue level of $325 \mathrm{mg} / \mathrm{kg}$ ) compared with other crops (tobacco, soybean, and rice), and the crop exhibited an excellent increase in the grain Se content for human consumption. The results noted the possibility of the use of sodium selenate for the biofortification of wheat in Australia [20, 53, 54].

The incorporation of organic by-products as soil conditioners and fertilisers has the advantage of recycling the macronutrients and micronutrients, enhancing the soil conditions, helping establish a sustainable vegetative cover, avoiding erosion, maximising crop yield when applied with best management practices, and monitoring potential hazards to soils and crops $[30,55]$.

\section{Use of Organic Fertilisers to Improve Se Content in Crops}

Organic matter is able to increase the sorption of selenate in arid conditions and to act as a reservoir for crops to avoid the leaching, evaporation, and precipitation of this species to deeper soil layers [56]. Thus, it is recommended in the management of Se fertilisation to avoid the consumption of expensive and unsustainable inorganic forms. Organic matter plays a very important role in selenium immobilisation and the availability of selenium to plants. This effect depends on the compounds because organic matter includes highly heterogeneous compounds and the interactions are not very well understood. In this particular case, fulvic and humic acids appear to have an important role on the metalloid regulation through immobilisation and slow release of organic forms of Se [56].

According to Park et al. [57] biosolids and especially poultry and livestock manure are a good source of Se for crops. These organic amendments contain bioavailable forms of this nutrient and are a useful form of amendment since in most cases they are applied to the land as a form of reutilisation of an increasing "waste" product. The addition of manure and organic amendments to agricultural soils is the major source of most micronutrients including Se and sewage sludge has the same Se forms as manure [12].
According to Øgaard et al. [58], the addition of cattle manure to a loam soil in combination with selenite and selenate decreased the adsorption and immobilisation of both anions because the organic acids from the manure compete with selenium for the sorption sites. Organic fertilisers provide greater micronutrient content to plants not only because of the higher concentration of these but also due to their slower release from the plant $[12,25,59]$.

In the case of recycling crop residues, such as straw, much of the added Se, that is, as much as $70-75 \%$, remains in the rest of the plant, particularly in leaves, which are a highly concentrated source of this element. This is also true for animal manures because most of the Se is not absorbed by the animal and because farmed animals are fed feedstuffs rich in Se, when animals are fed with forage supplements or are raised on Se-rich soils. Thus, organic fertilisers provide a diverse, albeit unpredictable, source of Se.

Se in organic amendments has been proved to have several advantages compared with inorganic Se fertilizers. For example, Se is bioavailable through several microbial and chemical processes including immobilization, reduction, volatilization, and rhizosphere modification (Figures 4 and 5). The bioavailability depends on several factors, the most important of which is $\mathrm{pH}$. In most of the case this availability is assured by the treatment of organic amendments, where bioavailability is increased by transforming Se from solid to the soil solution phase, improving the mobilisation of the metalloid [41] and increasing the $\mathrm{pH}$ buffering capacity.

Organic amendments to fertilise crop with Se offers an additional advantage in arid and semiarid environments since the removal of Se in topsoil is mostly due to volatilization $[60,61]$. Indeed, according to Flury et al. [62], the elimination of Se from topsoil mostly happens due to volatilization and leaching, Figure 5. These authors investigated Se removal from organic amendments and summarised that when an abundance of organic $\mathrm{C}$ was available in the soil, microbial biodegradation of $\mathrm{Se}$ is activated through volatilisation. In general, leaching dominates in wet and cold conditions, whereas volatilization prevails in dry and warm conditions.

\section{Conclusions}

Recent studies on human health have shown that the appropriate amounts of certain micronutrients in the diet are important for maintaining a healthy society. The evidence for this is especially true in the case of selenium (Se), where $15 \%$ of the global population has an insufficiency. The deficiency of this element in the human and animal diets is related to some cancers and numerous physiological disorders. Many countries have implemented Se-supplemented fertilisation strategies, mainly for the production of cereals, because wheat is the most widely used food for improving the amounts of Se in the diet. The issues of Se availability is especially crucial in arid and semiarid environments, where one of the main benefits of the micronutrient to crop production is an increase in the drought resistance, and where many of the soils that are low in selenium are located.

There are constraints that must be taken into account regarding the application of Se-supplemented fertilisers. 


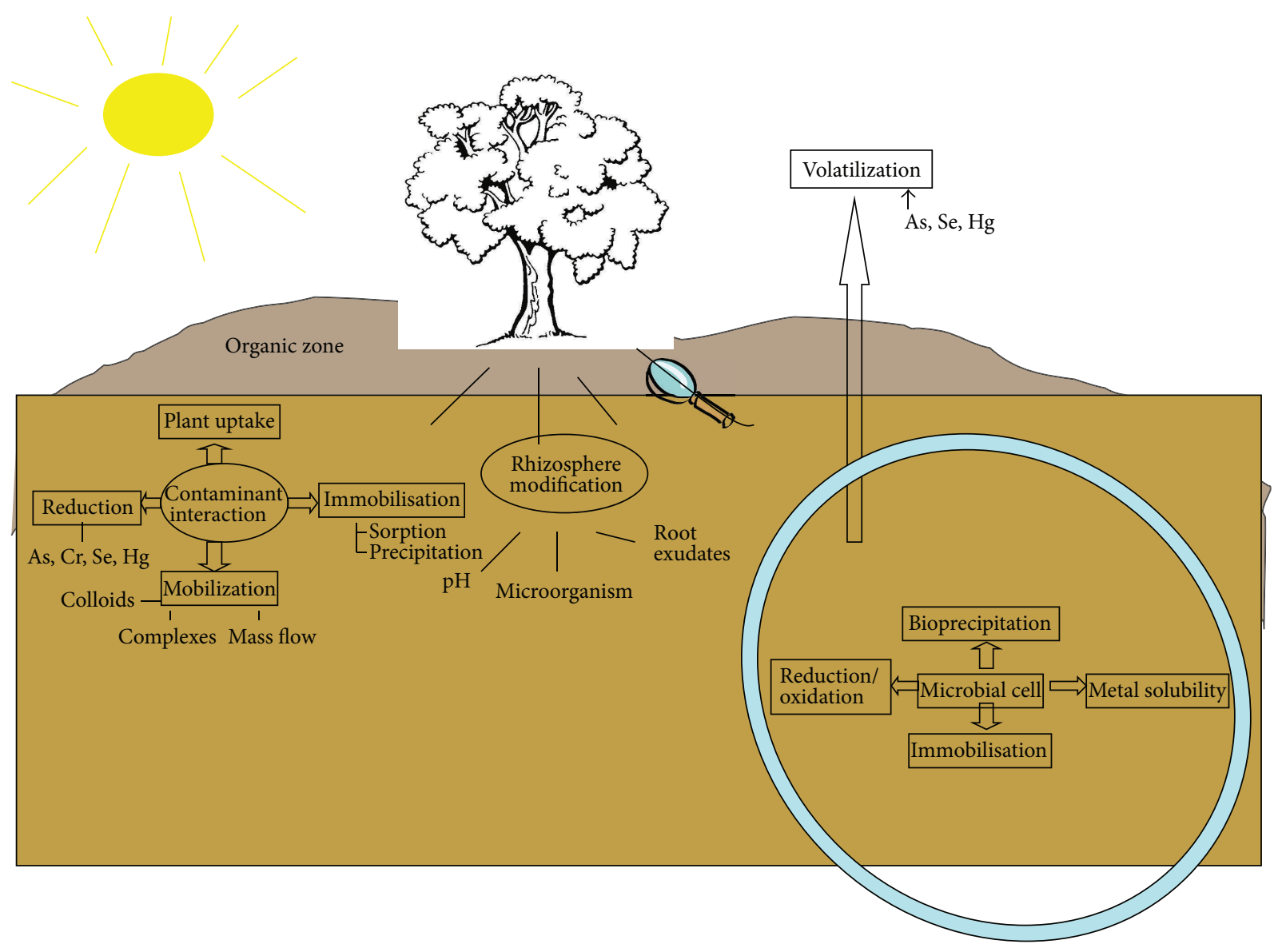

FIGURE 4: The role of organic amendments in regulating various bioremediation processes (extracted from [57]).

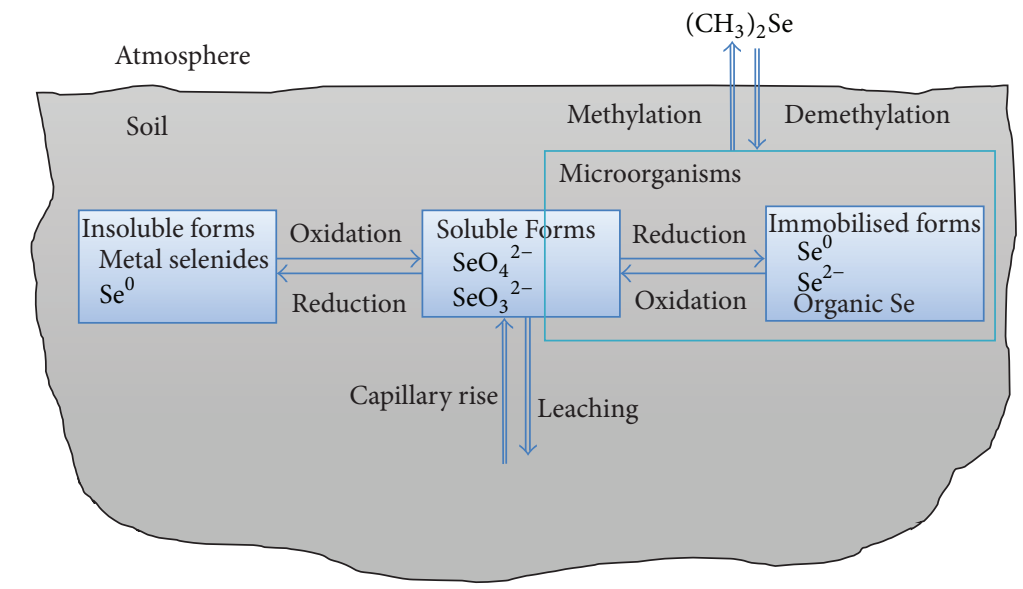

FIgURE 5: Cycle of Se in soil. Double arrows show preferred pattern for biodegradation (extracted from [62]).

Mineral biofortification has been proven to be effective; however, this strategy is limited by the availability of mineral resources and its cost [34]. Sustainable biofortification depends on the use of organic fertilisers and conditioners to improve micronutrient fertilisation, particularly Se fertilisation. Thus, as well as providing other better-known soil benefits, the addition of organic matter could become an important consideration to ensure a healthy Se content in wheat produced in semiarid conditions.

We have reviewed research conducted in this field and found that further studies must be performed to compare the performance of different sources of organic matter as a fertiliser including biosolids and especially poultry and livestock manure, straw, or any organic by-product, to ensure 
the appropriate levels of available Se, as well as other micronutrients, in the fertilisation of wheat to improve the micronutrition of the human diet. More research must be conducted to understand the speciation and release of Se from organic amendments, to improve the use of organic by-products, and to avoid the limitations related to the use of inorganic fertilisers. Finally, research must be focused on the need of each specific land location and crop to provide optimised Se contents for animal and plant intake, avoiding the immobilisation of this metal in soils. Therefore, specific recommendations must be done for specific organic amendments and agricultural uses to optimise uptake and avoid toxicity.

\section{References}

[1] P. J. White and M. R. Broadley, "Biofortification of crops with seven mineral elements often lacking in human diets-iron, zinc, copper, calcium, magnesium, selenium and iodine," New Phytologist, vol. 182, no. 1, pp. 49-84, 2009.

[2] J. L. Stroud, M. R. Broadley, I. Foot et al., "Soil factors affecting selenium concentration in wheat grain and the fate and speciation of Se fertilisers applied to soil," Plant and Soil, vol. 332, no. 1, pp. 19-30, 2010.

[3] D. Tennant, G. Scholz, J. Dixon, and B. Purdie, "Physical and chemical characteristics of duplex soils and their distribution in the south-west of Western Australia," Australian Journal of Experimental Agriculture, vol. 32, no. 7, pp. 827-843, 1992.

[4] U. C. Gupta, W. Kening, and L. Siyuan, "Micronutrients in soils, crops and livestock," Earth Science Frontiers, vol. 15, no. 5, pp. 110-125, 2008.

[5] G. Gissel-Nielsen, "Effects of selenium supplementation of field crops," in Environmental Chemistry of Selenium, W. T. Frankenberger and R. A. Engberg, Eds., pp. 99-112, Dekker, New York, NY, USA, 1998.

[6] P. Ekholm, H. Reinivuo, P. Mattila et al., "Changes in the mineral and trace element contents of cereals, fruits and vegetables in Finland," Journal of Food Composition and Analysis, vol. 20, no. 6, pp. 487-495, 2007.

[7] S. Mythili, K. Natarajan, and R. Kalpana, "Zinc nutrition in rice: a review," Agricultural Reviews, vol. 24, no. 2, pp. 136-141, 2003.

[8] G. Bañuelos and Z. Q. Lin, Development and Uses of Biofortified Agricultural Products, CRC Press, Boca Raton, Fla, USA, 2009.

[9] B. H. Robinson, G. Bañuelos, H. M. Conesa, M. W. H. Evangelou, and R. Schulin, "The phytomanagement of trace elements in soil," Critical Reviews in Plant Sciences, vol. 28, no. 4, pp. 240266, 2009.

[10] S. Hueso, T. Hernández, and C. García, "Resistance and resilience of the soil microbial biomass to severe drought in semiarid soils: the importance of organic amendments," Applied Soil Ecology, vol. 50, no. 1, pp. 27-36, 2011.

[11] P. M. Haygarth, "Global importance and global cycling of selenium," in Selenium in the Environment, W. T. Frankenberger and B. Sally, Eds., pp. 1-28, Marcel Dekker, New York, NY, USA, 1994.

[12] M. P. Rayman, "The argument for increasing selenium intake," Proceedings of the Nutrition Society, vol. 61, no. 2, pp. 203-215, 2002.

[13] M. F. Fenech, "Dietary reference values of individual micronutrients and nutriomes for genome damage prevention: current status and a road map to the future," American Journal of Clinical Nutrition, vol. 91, no. 5, pp. 1438S-1454S, 2010.

[14] G. W. Ford, J. J. Martin, P. Rengasamy, S. C. Boucher, and A. Ellington, "Soil sodicity in Victoria," Australian Journal of Soil Research, vol. 31, no. 6, pp. 869-909, 1993.

[15] M. R. Broadley, P. J. White, R. J. Bryson et al., "Biofortification of UK food crops with selenium," Proceedings of the Nutrition Society, vol. 65, no. 2, pp. 169-181, 2006.

[16] F. Fordice, "Selenium deficiency and toxicity in the environment," in Essentials of Medical Geology, O. Selinus, B. Alloway, J. Centeno et al., Eds., pp. 373-415, Elsevier, London, UK, 2005.

[17] D. V. Frost, "What do losses in selenium and arsenic bioavailability signify for health?" Science of the Total Environment, vol. 28, pp. 455-466, 1983.

[18] National Academy of Sciences, Recommended Dietary Allowances, National Academy of Sciences, Washington, DC, USA, 10th edition, 1989.

[19] J. Lee, D. G. Masters, C. L. White, N. D. Grace, and G. J. Judson, "Current issues in trace element nutrition of grazing livestock in Australia and New Zealand," Australian Journal of Agricultural Research, vol. 50, no. 8, pp. 1341-1364, 1999.

[20] A. D. Lemly, "Guidelines for evaluating selenium data from aquatic monitoring and assessment studies," Environmental Monitoring and Assessment, vol. 28, no. 1, pp. 83-100, 1993.

[21] O. A. Levander and R. F. Burk, "Uptake of human dietary standards for selenium," in Selenium Its Molecular Biology and Role in Human Health, D. L. Hatfield, M. J. Berry, and V. N. Gladyshev, Eds., pp. 399-410, Springer, New York, NY, USA, 2nd edition, 2006.

[22] G. Lyons, "Selenium in cereals: improving the efficiency of agronomic biofortification in the UK," Plant and Soil, vol. 332, no. 1, pp. 1-4, 2010.

[23] J. Wu, C. Salisbury, R. Graham, G. Lyons, and M. Fenech, "Increased consumption of wheat biofortified with selenium does not modify biomarkers of cancer risk, oxidative stress, or immune function in healthy Australian males," Environmental and Molecular Mutagenesis, vol. 50, no. 6, pp. 489-501, 2009.

[24] K. Schwarz and C. M. Foltz, "Selenium as an integral part of factor 3 against dietary necrotic liver degeneration," Journal of the American Chemical Society, vol. 79, no. 12, pp. 3292-3293, 1957.

[25] K. Kaur, R. K. Jalota, and D. J. Midmore, "Impact of tree clearing on soil attributes for a pastoral property in central Queensland, Australia," Soil Science, vol. 172, no. 7, pp. 516-533, 2007.

[26] K. M. Havstad, J. E. Herrick, and W. H. Schlesinger, "Desert rangelends, degradation and nutrients," in Rangeland Desertification, O. Arnalds and S. Archer, Eds., pp. 77-87, Kluwer Academic Publishers, Dordrecht, The Netherlands, 2000.

[27] E. A. Pilon-Smits, C. F. Quinn, W. Tapken, M. Malagoli, and M. Schiavon, "Physiological functions of beneficial elements," Current Opinion in Plant Biology, vol. 12, no. 3, pp. 267-274, 2009.

[28] C. D. Thomson, "Assessment of requirements for selenium and adequacy of selenium status: a review," European Journal of Clinical Nutrition, vol. 58, no. 3, pp. 391-402, 2004.

[29] M. P. Rayman, "Food-chain selenium and human health: emphasis on intake," British Journal of Nutrition, vol. 100, no. 2, pp. 254-268, 2008.

[30] G. J. Judson and D. J. Reuter, Soil Analysis: An Interpretation Manual, South Australia Research \& Development Institute (SARDI), Urrbrae, South Australia, 1998. 
[31] G. H. Lyons, J. C. R. Stangoulis, and R. D. Graham, "Tolerance of wheat (Triticum aestivum L.) to high soil and solution selenium levels," Plant and Soil, vol. 270, no. 1, pp. 179-188, 2005.

[32] J. D. Rosen, "A Review of the nutrition claims made by proponents of organic food," Comprehensive Reviews in Food Science and Food Safety, vol. 9, no. 3, pp. 270-277, 2010.

[33] K. Nakamuro, K. Nakanishi, T. Okuno, T. Hasegawa, and Y. Sayato, "Comparison of methylated selenium metabolites in rats after oral administration of various selenium compounds," Japanese Journal of Toxicology and Environmental Health, vol. 43, no. 1, pp. 1482-1489, 1997.

[34] T. Hasegawa, M. Mihara, K. Nakamuro, and Y. Sayato, "Mechanisms of selenium methylation and toxicity in mice treated with selenocystine," Archives of Toxicology, vol. 71, no. 1-2, pp. 31-38, 1996.

[35] Y. G. Zhu, E. A. H. Pilon-Smits, F. J. Zhao, P. N. Williams, and A. A. Meharg, "Selenium in higher plants: understanding mechanisms for biofortification and phytoremediation," Trends in Plant Science, vol. 14, no. 8, pp. 436-442, 2009.

[36] G. Lyons, I. Ortiz-Monasterio, J. Stangoulis, and R. Graham, "Selenium concentration in wheat grain: is there sufficient genotypic variation to use in breeding?" Plant and Soil, vol. 269, no. 1-2, pp. 369-380, 2005.

[37] M. H. Eurola, P. I. Ekholm, M. E. Ylinen, P. E. Koivistoinen, and P. T. Varo, "Selenium in finish foods after beginning the use of selenate-supplemented fertilisers," Journal of the Science of Food and Agriculture, vol. 56, pp. 57-70, 1991.

[38] M. R. Broadley, J. Alcock, J. Alford et al., "Selenium biofortification of high-yielding winter wheat (Triticum aestivum L.) by liquid or granular Se fertilisation," Plant and Soil, vol. 332, no. 1, pp. 5-18, 2010.

[39] M. Eurola, V. Hietaniemi, M. Kontturi et al., "Selenium content of Finnish oats in 1997-1999: effect of cultivars and cultivation techniques," Agricultural and Food Science, vol. 13, no. 1-2, pp. 46-53, 2004.

[40] I. Bertrand, R. E. Holloway, R. D. Armstrong, and M. J. McLaughlin, "Chemical characteristics of phosphorus in alkaline soils from southern Australia," Australian Journal of Soil Research, vol. 41, no. 1, pp. 61-76, 2003.

[41] M. A. Bowker, J. Belnap, D. W. Davidson, and S. L. Phillips, "Evidence for micronutrient limitation of biological soil crusts: importance to arid-lands restoration," Ecological Applications, vol. 15, no. 6, pp. 1941-1951, 2005.

[42] H. Hartikainen, "Biogeochemistry of selenium and its impact on food chain quality and human health," Journal of Trace Elements in Medicine and Biology, vol. 18, no. 4, pp. 309-318, 2005.

[43] A. D. Robson, N. E. Longnecker, and L. D. Osborne, "Effects of heterogeneous nutrient supply on root growth and nutrient uptake in relation to nutrient supply on duplex soils," Australian Journal of Experimental Agriculture, vol. 32, no. 7, pp. 879-886.

[44] W. H. Schlesinger, J. F. Reynolds, G. L. Cunningham et al., "Biological feedbacks in global desertification," Science, vol. 247, no. 4946, pp. 1043-1048, 1990.

[45] Z. Rengel, G. D. Batten, and D. E. Crowley, "Agronomic approaches for improving the micronutrient density in edible portions of field crops," Field Crops Research, vol. 60, no. 1-2, pp. 27-40, 1999.

[46] H. F. Li, S. P. McGrath, and F. J. Zhao, "Selenium uptake, translocation and speciation in wheat supplied with selenate or selenite," New Phytologist, vol. 178, no. 1, pp. 92-102, 2008.
[47] P. Pathak, K. L. Sahrawat, S. P. Wani, R. C. Sachan, and R. Sudi, "Opportunities for water harvesting and supplemental irrigation for improving rainfed agriculture in semi-arid areas," in Rainfed Agriculture: Unlocking the Potential. Comprehensive Assessment of Water in Agriculture Series, S. P. Wani, J. Rockström, and T. Oweis, Eds., vol. 7, pp. 197-221, CAB International, Wallingford, UK, 2009.

[48] A. Bationo, J. Kihara, V. Vanlauwe, J. Kimetu, B. S. Waswa, and K. L. Sahrawat, "Integrated nutrient managemenr: concepts and experience form Sub-Saharan Africa," in Integrated Nutrient Management for Sustainable Crop Production, M. S. Auklakh and C. A. Grant, Eds., pp. 467-521, The Haworth Press-Taylor and Francis, New York, NY, USA, 2008.

[49] A. D. Sparrow, M. H. Friedel, and D. J. Tongway, "Degradation and recovery processes in arid grazing lands of central Australia. Part 3: implications at landscape scale," Journal of Arid Environments, vol. 55, no. 2, pp. 349-360, 2003.

[50] N. E. Spencer and S. M. Siegel, "Effects of sulfur and selenium oxyanions on Hg-toxicity in turnip seed germination," Water, Air, and Soil Pollution, vol. 9, no. 4, pp. 423-427, 1978.

[51] S. H. Van Dorst and P. J. Peterson, "Selenium speciation in the soil solution and its relevance to plant uptake," Journal of the Science of Food and Agriculture, vol. 35, pp. 601-605, 1984.

[52] V. V. Kuznetsov, V. P. Kholodova, V. V. Kuznetsov, and B. A. Yagodin, "Selenium regulates the water status of plants exposed to drought," Dokaldy Biological Sciences, vol. 390, no. 1-6, pp. 266-268, 2003.

[53] M. A. Elrashidi, D. C. Adriano, and W. L. Lindsay, "Solubility, speciation and transformations of selenium in soils," in Selenium in Agriculture and the Environment, L. W. Jacobs, Ed., Special Publication Number 23, pp. 51-63, SSSA, Madison, Wis, USA, 1989.

[54] M. S. Fan, F. J. Zhao, P. R. Poulton, and S. P. McGrath, "Historical changes in the concentrations of selenium in soil and wheat grain from the Broadbalk experiment over the last 160 years," Science of the Total Environment, vol. 389, no. 2-3, pp. 532-538, 2008.

[55] R. K. Bastian, "Interpreting science in the real world for sustainable land application," Journal of Environmental Quality, vol. 34, no. 1, pp. 174-183, 2005.

[56] A. Fernández-Martínez and L. Charlet, "Selenium environmental cycling and bioavailability: a structural chemist point of view," Reviews in Environmental Science and Biotechnology, vol. 8, no. 1, pp. 81-110, 2009.

[57] J. H. Park, D. Lamb, P. Paneerselvam, G. Choppala, N. Bolan, and J. W. Chung, "Role of organic amendments on enhanced bioremediation of heavy metal(loid) contaminated soils," Journal of Hazardous Materials, vol. 185, no. 2-3, pp. 549-574, 2011.

[58] A. F. Øgaard, T. A. Sogn, and S. Eich-Greatorex, "Effect of cattle manure on selenate and selenite retention in soil," Nutrient Cycling in Agroecosystems, vol. 76, no. 1, pp. 39-48, 2006.

[59] M. P. Rayman, H. G. Infante, and M. Sargent, "Food-chain selenium and human health: spotlight on speciation," British Journal of Nutrition, vol. 100, no. 2, pp. 238-253, 2008.

[60] W. T. Frankenberger Jr. and U. Karlson, "Soil management factors affecting volatilization of selenium from dewatered sediments," Geomicrobiology Journal, vol. 12, no. 4, pp. 265-278, 1994.

[61] W. T. Frankenberger Jr. and U. Karlson, "Volatilization of selenium from a dewatered seleniferous sediment: a field study," Journal of Industrial Microbiology, vol. 14, no. 3-4, pp. 226-232, 1995. 
[62] M. Flury, W. T. Frankenberger Jr., and W. A. Jury, "Long-term depletion of selenium from Kesterson dewatered sediments," Science of the Total Environment, vol. 198, no. 3, pp. 259-270, 1997. 

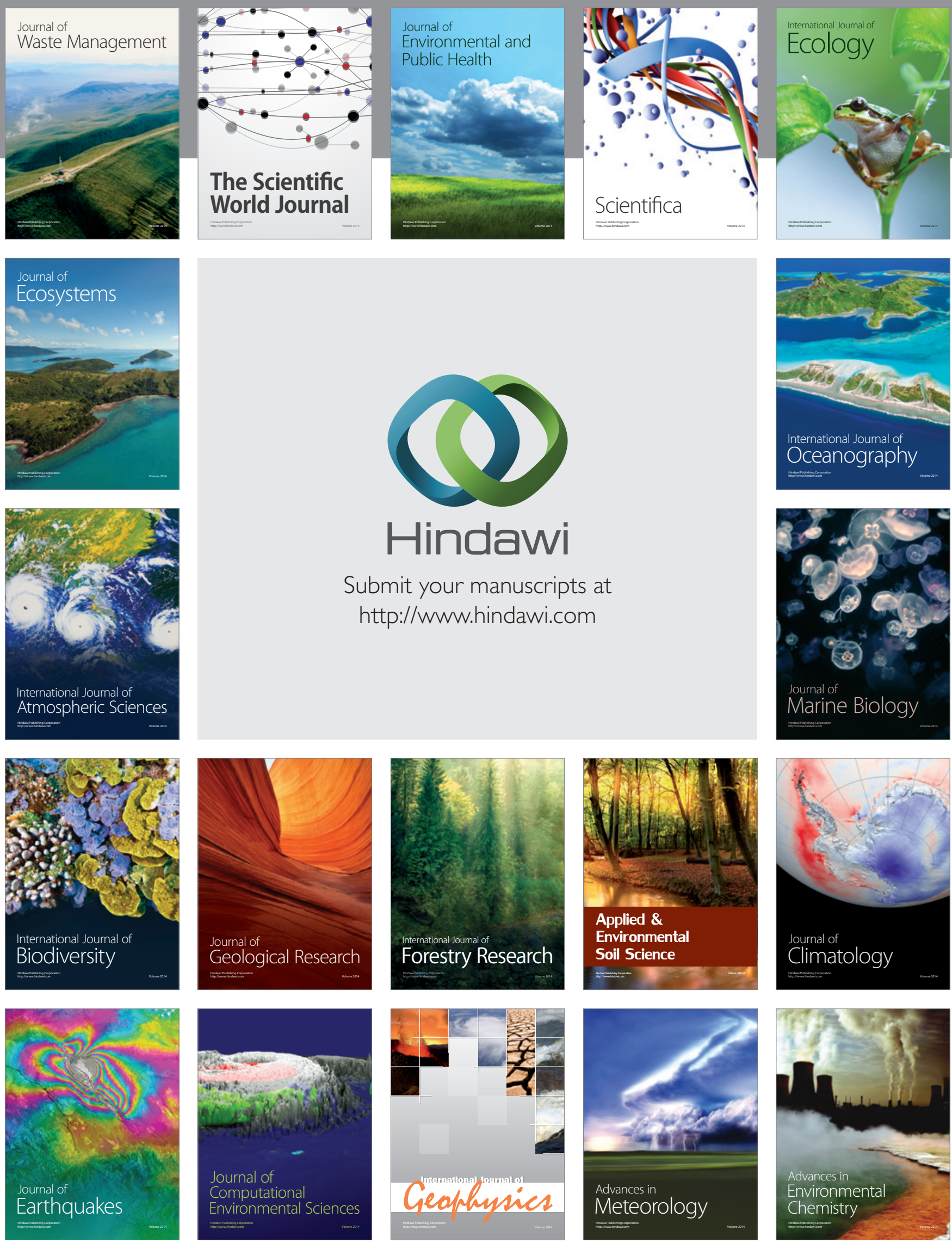